\title{
Understanding Plant Responses to Drought: How Important is Woody Tissue Photosynthesis?
}

\author{
J. Bloemen, L. Overlaet-Michiels and K. Steppe \\ Laboratory of Plant Ecology \\ Faculty of Bioscience Engineering, Ghent University \\ Gent \\ Belgium
}

Keywords: woody tissue photosynthesis, tree growth, tree carbon balance, photosynthesis

\begin{abstract}
Within trees, it is known that a part of the respired $\mathrm{CO}_{2}$ is assimilated in chlorophyll-containing stem and branch tissues. However the role of this woody tissue photosynthesis in tree functioning remains unclear, in particular under drought stress conditions. In this study, stem diameter and leaf photosynthesis were measured for one-year-old cutting-derived plants of Populus nigra "Monviso" under both well-watered and drought stress conditions. Half of the plants were subjected to a stem and branch light-exclusion treatment to prevent woody tissue photosynthesis to occur, while the other trees served as controls. Drought stress was induced in both treatments by limiting the water supply. We found that under wellwatered conditions, light-exclusion resulted in reduced stem radial daily growth rate (DG) relative to DG observed for control trees. In response to drought, stem shrinkage of the light-excluded trees was more pronounced as compared to the control trees. Maximum leaf net photosynthesis $\left(A_{\max }\right)$ decreased more rapidly in light-excluded trees compared to the controls during drought stress. Our results are the first to report on the potentially significant role of woody tissue photosynthesis in tree drought stress tolerance. Moreover, our study implies that the impact of assimilation of respired $\mathrm{CO}_{2}$ on tree functioning extends beyond local stem processes and indicates that woody tissue photosynthesis is potentially a key factor in understanding plant responses to drought stress.
\end{abstract}

\section{INTRODUCTION}

Within trees, chlorophyll-containing tissues in the bark and xylem of stem and branches have been found to play a role in carbon assimilation. By assimilating respired $\mathrm{CO}_{2}$, which is present inside trees at high concentrations (ranging from $<1 \%$ to over $26 \%$ (Teskey et al., 2008)), these photosynthetically active tissues photo-reduce $\mathrm{CO}_{2}$ similarly as described for green leaves (Pfanz et al., 2002). This re-assimilated $\mathrm{CO}_{2}$ would otherwise be "lost" to the surrounding atmosphere, which explains why woody tissue photosynthesis is often described within the context of a tree carbon recycling mechanism. Wittmann et al. (2006) found that woody tissue photosynthesis was able to assimilate up to $97 \%$ of the $\mathrm{CO}_{2}$ in young birch. Other studies reported similar reassimilation rates of respired $\mathrm{CO}_{2}$ by woody tissue photosynthesis for other trees species (see Table 4 in Pfanz et al., 2002), but under normal conditions the overall impact of woody tissue photosynthesis on plant carbon economy is expected to be limited. 
Nevertheless, woody tissue photosynthesis might play an important role during particular stress events. Different authors consider woody tissue photosynthesis as a potentially important means of bridging the carbon balance between defoliation and refoliation (Bossard and Rejmanek, 1992; Pfanz, 2008; Eyles et al., 2009) or during bud development (Saveyn et al., 2010). Other studies suggest that woody tissue photosynthesis might improve the stem carbon balance under limited water availability (Wittmann and Pfanz, 2008). For instance, in desert and semi-desert non-succulent species, stem photosynthesis can be crucial in plant survival by contributing substantially to plant carbon gain (Nilsen and Sharifi, 1994; Nilsen, 1995; Aschan and Pfanz, 2003). For temperate forest species under moderate drought stress, decreased stomatal conductance might limit the assimilation of atmospheric $\mathrm{CO}_{2}$ in the leaves (Flexas and Medrano, 2002; Chaves et al., 2003), whereas woody tissue photosynthesis is supplied by endogenously respired $\mathrm{CO}_{2}$ (Pfanz et al., 2002; Aschan and Pfanz, 2003; Wittmann and Pfanz, 2008). Therefore, the fraction of tree carbon derived from woody tissue photosynthesis might become more important under drought stress.

However, the actual role of woody tissue photosynthesis in tree response to drought stress is not yet understood. Schmitz et al. (2012) observed that woody tissue photosynthesis in xylary chloroplasts might be important for the light-dependent repair of embolized xylem vessels, which is crucial for maintaining hydraulic function, in particular during drought stress. Therefore, by maintaining the carbon balance as well as the water status, woody tissue photosynthesis might play a crucial dual role in tree drought stress tolerance.

In this study, we investigated the importance of woody tissue photosynthesis in trees under drought stress and well-watered conditions. Under both conditions, we measured photosynthesis at leaf level and diameter growth at stem level (manually and automated) for both control and light-excluded one-year-old poplar trees (Populus nigra 'Monviso'). We hypothesized that woody tissue photosynthesis will impact tree carbon gain both under sufficient water supply and during drought stress. Moreover, we hypothesized that light-excluded trees would suffer faster and more dramatically from drought stress than (non light-excluded) control trees.

\section{MATERIALS AND METHODS}

\section{Plant Material and Experimental Design}

One-year-old cutting-derived plants of Populus nigra "Monviso" were used for this study. Twelve cuttings were planted at the end of June 2012 in $50 \mathrm{~L}$ containers filled with a potting mixture (LP502D, Peltracom nv, Gent, Belgium) and slow-releasing fertilizer (Basacot Plus 6M, Compo Benelux nv, Deinze, Belgium), and grown within the greenhouse facility at the Faculty of Bioscience Engineering, Ghent University, Gent, Belgium. Eight plants were selected based on uniform height and stem diameter and randomly assigned between the two treatments. Four plants served as control, while the four others were selected for the light-exclusion treatment, which started on 2 August 2012 (Day of the year, DOY 214). The stem and woody branches of these light-excluded trees were loosely wrapped with aluminium foil to enable gaseous diffusion from woody tissues to the atmosphere. Initially, all plants were irrigated at least twice a week, ensuring adequate water supply. On 30 September 2012 (DOY 273) drought stress was imposed by withholding water supply from all trees. No leaf fall occurred until one week after the start of the drought stress. Leaf area was determined by randomly sampling ten 
leaves per tree that fell off due to drought stress and multiplying this average leaf area with the number of leaves per tree. Leaf area ranged from 4.7-3.2 $\mathrm{m}^{2}$ and 3.9-2.8 $\mathrm{m}^{2}$ for the control and light-excluded trees respectively and average leaf area was not different between both treatments.

\section{Microclimate and Plant Measurements}

Relative humidity $(\mathrm{RH})$ was measured in the greenhouse with a capacitive $\mathrm{RH}$ sensor (Type hih-3610, Honeywell, Morristown, NJ, USA), air temperature $\left(\mathrm{T}_{\text {air }}\right)$ with a copper constantan thermocouple (Type T, Omega, Amstelveen, USA), and photosynthetic active radiation (PAR) with a quantum sensor (LI-190S, Li-COR, Lincoln, TE, USA). Sensors were installed at a height of approximately $2 \mathrm{~m}$.

Plant measurements were performed from the beginning of July 2012 until midOctober 2012. At stem level, stem diameter was continuously measured with linear variable displacement transducers (LVDT; model DF5.0, Solartron Metrology, Bognor Regis, UK), installed on one control trees and one light-excluded tree. Stem radial daily growth rate (DG, mm day ${ }^{-1}$ ) was calculated as the difference between two successive daily maximum values of the stem diameter. On 21 September 2012 (DOY 264), before the start of the drought stress, two additional trees (one control and one light-excluded tree) were instrumented with LVDT sensors. Continuous stem diameter measurements were complemented with weekly calliper-based manual measurements. Manual stem diameter data were derived from two measurements at a height of $30 \mathrm{~cm}$ along perpendicular lines. Average DG derived from the manual measurements was calculated as the difference between two successive measurements divided by the time period between both measurements.

At leaf level, maximum net photosynthesis $\left(A_{\max }, \mu \mathrm{mol} \mathrm{CO}_{2} \mathrm{~m}^{-2} \mathrm{~s}^{-1}\right)$ was measured on all trees on a fully expanded leaf with a portable photosynthesis system (model Li6400, Li-Cor, Inc., Lincoln, Nebraska, USA). Measurements were performed at $25^{\circ} \mathrm{C}$, prevailing $\mathrm{RH}$ conditions and at a set atmospheric $\mathrm{CO}_{2}$ concentration of $400 \mathrm{ppm}$ and a PAR level of $1500 \mu \mathrm{mol} \mathrm{m} \mathrm{m}^{-2} \mathrm{~s}^{-1}$. The latter was determined via a preliminary experiment in which light response curves were obtained for leaves of six plants. Measurements were performed biweekly during the period before the drought stress experiment, and at a twoday interval during the drought stress treatment. At each measurement time, the average of five measurements recorded at $10-\mathrm{sec}$ intervals was used for the analysis.

\section{Data and Statistical Analysis}

Data from automated measurements was recorded at 1-min intervals with a datalogger (CR1000, Campbell Scientific, Logan, Utah, USA) and averaged over 30-min intervals. Data were analyzed using Excel 2007 (Microsoft Inc., Redmond, WA, USA). DG derived from manual and automatic measurements, as well as $\mathrm{A}_{\max }$ were analyzed using a repeated measures multi-factorial analysis of variance (ANOVA). Analyzed DG data from manual measurements was confined to those taken during the well-watered conditions with treatment $(\mathrm{n}=2)$ and days $(\mathrm{n}=16)$ treated as fixed factors and individual tree $(n=8)$ as random factor. A similar model was used to analyze DG data from automatic measurements. In this case our data was derived from a lower number of individual trees $(n=4)$ and confined to the measurements taken one week before and during the drought stress treatment (days: $n=16$ ). Similarly, $A_{\max }$ measurements were confined to those taken during the drought stress treatment (date: $n=12$ ) with a higher number of tree replicates (individual tree: $n=8$ ). Treatment means were compared using 
Fisher's least significant difference (LSD) test. Akaike Information Criterion (AIC) was used to determine the covariance structure that best estimated the correlation among individual trees over time. All analyses were performed using the mixed model procedure (PROC MIXED) of SAS (Version 9.1.3, SAS Inc., Cary, NC, USA) with $\alpha=0.05$.

\section{RESULTS}

\section{Daily Growth Rate}

Light-exclusion of the stem and woody branches had an impact on tree DG both under well-watered and drought conditions. Before light-exclusion, DG derived from manual stem diameter measurements was similar for both treatments (Fig. 1). However, as soon as light-exclusion was applied, DG of light-excluded trees was systematically lower than those calculated for the control trees. Significant differences $(P<0.05)$ in DG between both treatments were observed at specific dates throughout the well-watered period. The average stem diameter increment over the period July-September was smaller for the light-excluded trees $(4.00 \pm 0.12 \mathrm{~mm})$ than for the control trees $(5.28 \pm 0.57 \mathrm{~mm})$, indicating a $24 \%$ impact of light-exclusion on DG during the period July-September.

Under drought stress, LVDT-based measurements indicated that the stems of both the control and light-excluded trees shrank, resulting in a negative DG (Fig. 2). Before the onset of drought stress, DG estimates were within the same range as observed for estimates from manually derived measurements (Fig. 1). During drought stress, DG of control trees decreased gradually over time, as expected. However, DG of light-excluded trees increased until five days after the start of the drought stress. Thereafter, DG started to decrease to a level lower than observed for the control trees, indicating that at this time light-excluded trees were most likely shrinking faster than control trees (Fig. 2).

\section{Maximum Net Photosynthesis}

Light-exclusion of stem and woody branches had an additional impact on $\mathrm{A}_{\max }$ during drought stress (Fig. 3). Before drought stress, similar $A_{\max }$ was observed for the leaves of the control and light-excluded trees. After drought stress, the onset of the decrease in $A_{\max }$ for light-excluded trees was about three days earlier than for control trees (4 October vs. 7 October) and was approximately simultaneous to the onset of the decrease in DG (Fig. 2). Finally, at the end of the drought stress period, similar $A_{\max }$ rates were observed for both treatments.

\section{DISCUSSION}

Our results confirm previous findings on the importance of woody tissue photosynthesis contribution to the carbon income of plants. We observed that under wellwatered conditions light-exclusion of stem and woody branches resulted in a decreased growth rate for Populus nigra. Previously, Saveyn et al. (2010) performed a similar lightexclusion treatment combined with stem diameter measurements and found a similar effect of light-exclusion on trunk diameter increment. Based on isotope analysis of wood samples of covered and uncovered branch sections of Eucalyptus miniata, Cernusak and Hutley (2011) calculated that $11 \%$ of newly formed branch tissue was constructed from stem assimilates. Our estimates of stem increment during the period July-September for control and light-excluded trees indicate that the contribution of woody tissue photosynthesis to stem growth was around $24 \%$ for Populus nigra. 
More importantly, our study is the first to show that woody tissue photosynthesis might play an important role in tree drought stress tolerance when atmospheric $\mathrm{CO}_{2}$ assimilation becomes limited (e.g. Pfanz et al., 2002). In response to severe drought stress, stem shrinkage tended to be higher for light-excluded than for control trees. Moreover, leaf photosynthesis was found to decline more rapidly for shaded trees under drought relative to control trees. Therefore, in contrast to previous assumptions (Wittmann and Pfanz, 2008), the role of woody tissue photosynthesis in tree drought stress tolerance might extent beyond maintaining the plant carbon status at stem level.

\section{CONCLUSIONS}

We have shown that woody tissue photosynthesis plays an important role in tree growth and in tree drought stress tolerance. Our measurements are the first that indicate that stem assimilation of respired $\mathrm{CO}_{2}$ might play a crucial role in tree physiological responses to drought stress. Therefore, woody tissue photosynthesis should be considered in future studies on the tree carbon economy, in particular when aiming at a full understanding of plant responses to drought.

\section{ACKNOWLEDGEMENTS}

The authors wish to thank Philip Deman and Geert Favyts of the Laboratory of Plant Ecology for their enthusiastic technical support. This project was supported by a starting grant from the Special Research Fund (BOF) of Ghent University to KS.

\section{Literature Cited}

Aschan, G. and Pfanz, H. 2003. Non-foliar photosynthesis - a strategy of additional carbon acquisition. Flora 198:81-97.

Bossard, C.C. and Rejmanek, M. 1992. Why Have Green Stems. Funct. Ecol. 6:197-205.

Cernusak, L.A. and Hutley, L.B. 2011. Stable Isotopes Reveal the Contribution of Corticular Photosynthesis to Growth in Branches of Eucalyptus miniata. Plant Physiol. 155: 515-523.

Chaves, M.M., Maroco, J.P. and Pereira, J.S. 2003. Understanding plant responses to drought - from genes to the whole plant. Funct. Plant Biol. 30:239-264.

Eyles, A., Pinkard, E.A., O'Grady, A.P., Worledge, D. and Warren, C.R. 2009. Role of corticular photosynthesis following defoliation in Eucalyptus globulus. Plant Cell Environ. 32:1004-1014.

Flexas, J. and Medrano, H. 2002. Drought-inhibition of photosynthesis in C-3 plants: Stomatal and non-stomatal limitations revisited. Ann. Bot.-London 89:183-189.

Nilsen, E.T. and Sharifi, M.R. 1994. Seasonal Acclimation of Stem Photosynthesis in Woody Legume Species from the Mojave and Sonoran Deserts of California. Plant Physiol. 105:1385-1391.

Nilsen, E.T. 1995. Stem photosynthesis: Extent, Patterns and Role in Plant Carbon Economy. In: Gartner B. L. ed. Plant Stems: Physiology and Functional Morphology. San Diego, CA: Academic Press.

Pfanz, H., Aschan, G., Langenfeld-Heyser, R., Wittmann, C. and Loose, M. 2002. Ecology and ecophysiology of tree stems: corticular and wood photosynthesis. Naturwissenschaften 89:147-162.

Pfanz, H. 2008. Bark photosynthesis. Trees-Struct. and Funct. 22:137-138. 
Saveyn, A., Steppe, K., Ubierna, N. and Dawson, T.E. 2010. Woody tissue photosynthesis and its contribution to trunk growth and bud development in young plants. Plant Cell Environ. 33:1949-1958.

Schmitz, N., Egerton, J.J.G., Lovelock, C.E. and Ball, M.C. 2012. Light-dependent maintenance of hydraulic function in mangrove branches: do xylary chloroplasts play a role in embolism repair? New Phytol. 195:40-46.

Teskey, R.O., Saveyn, A., Steppe, K. and McGuire, M.A. 2008. Origin, fate and significance of $\mathrm{CO}_{2}$ in tree stems. New Phytol 177:17-32.

Wittmann, C., Pfanz, H., Loreto, F., Centritto, M., Pietrini, F. and Alessio, G. 2006. Stem $\mathrm{CO}_{2}$ release under illumination: corticular photosynthesis, photorespiration or inhibition of mitochondrial respiration? Plant Cell Environ. 29:1149-1158.

Wittmann, C. and Pfanz, H. 2008. Antitranspirant functions of stem periderms and their influence on corticular photosynthesis under drought stress. Trees-Struct. Funct. 22:187-196.

Figures

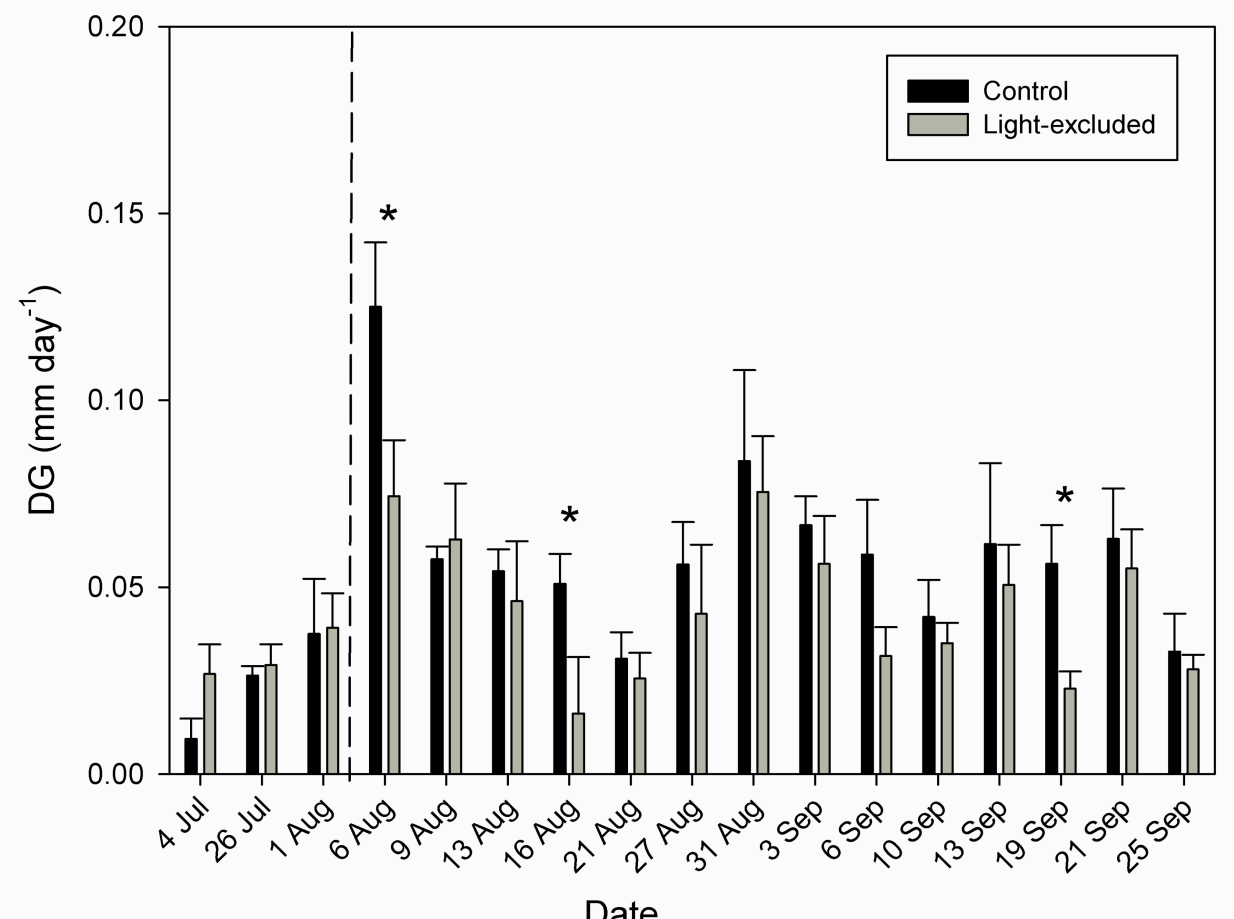

Fig. 1. Stem radial daily growth rate (DG) under well-watered conditions derived from manual stem diameter measurements and averaged for control and light-excluded trees ( $\mathrm{n}=4$ per treatment). DG was calculated as the difference between two successive measurements of the stem diameter divided by the time period between both measurements. The dashed line indicates the start of light-exclusion of the stem and woody branches. Asterisks indicate significant $(P<0.05)$ differences in DG between both treatments at each observation. Bars indicate standard error of the mean. 


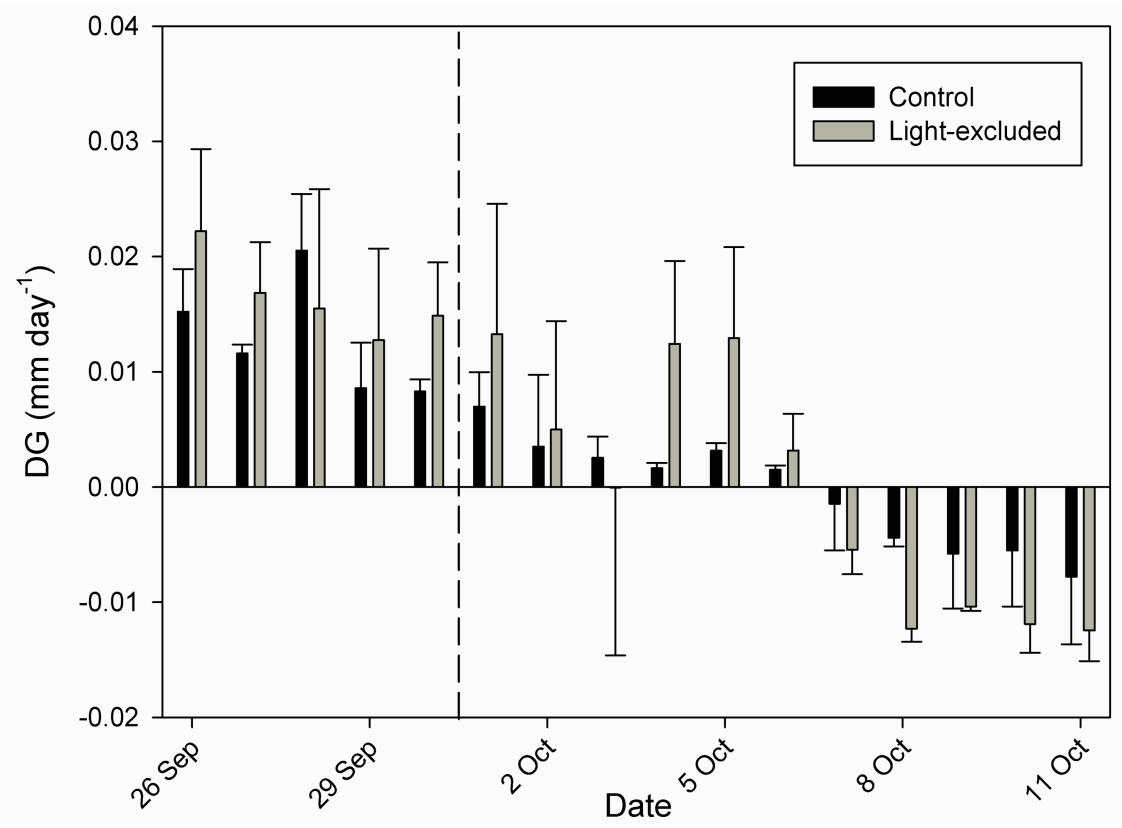

Fig. 2. Stem radial daily growth rate (DG) before and during drought stress derived from continuous measurements of stem diameter and averaged for control and lightexcludes trees ( $n=2$ per treatment). DG was calculated as the difference between two successive daily maximum values of the stem diameter. The dashed line indicates the timing of last irrigation before the onset of drought stress. No significant differences $(P<0.05)$ in DG between both treatments were observed. Bars indicate standard error of the mean.

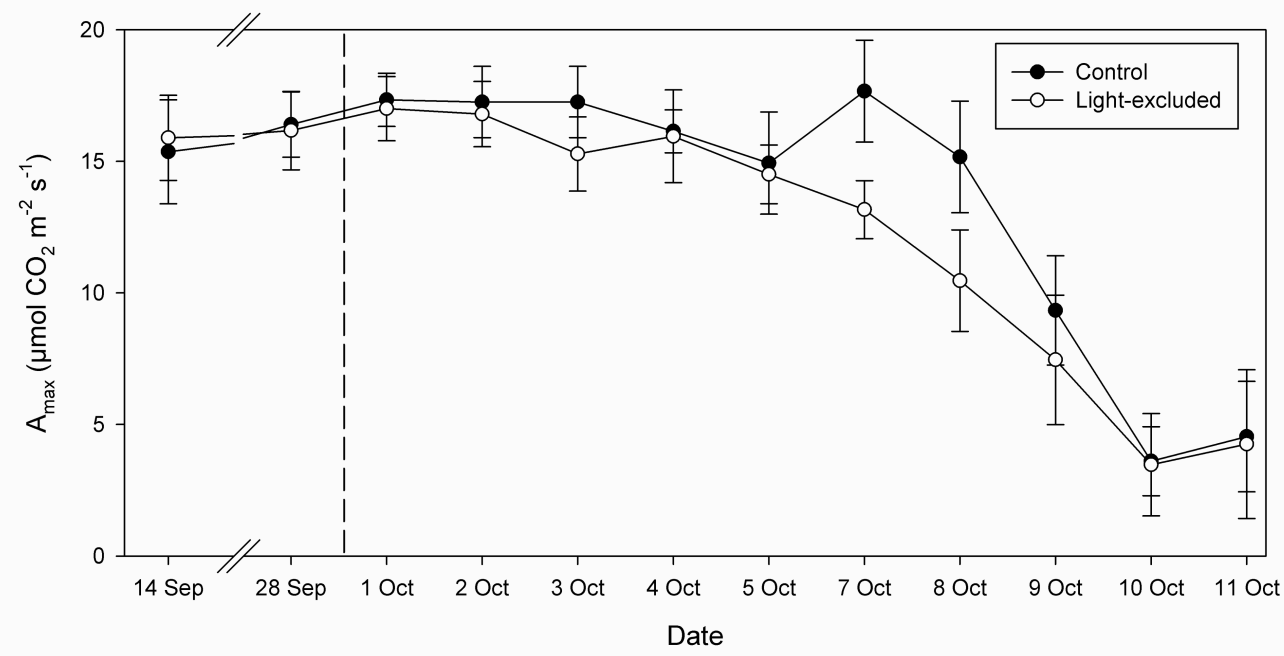

Fig. 3. Maximum leaf net photosynthesis $\left(\mathrm{A}_{\max }\right)$ before and during drought stress averaged for control and light-excluded trees $(n=4$ per treatment). The dashed line indicates the timing of last irrigation before the onset of drought stress. No significant differences $(P<0.05)$ in $\mathrm{A}_{\max }$ between both treatments were observed. Bars indicate standard error of the mean. 